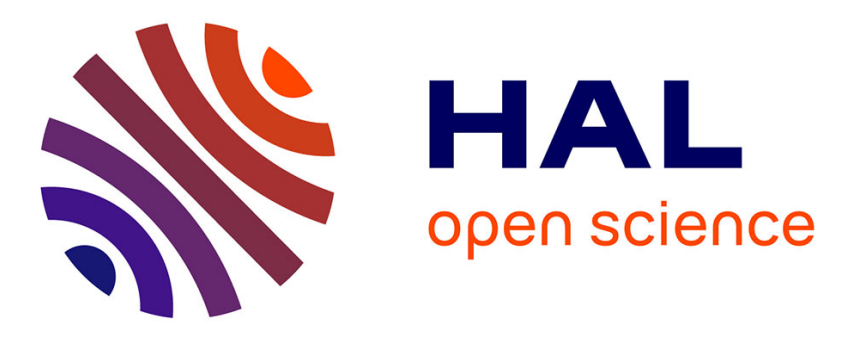

\title{
Thermostatted kinetic theory approach to the competition between cancer and immune system cells in an inhomogeneous system
}

\author{
Léon Masurel, Carlo Bianca, Annie Lemarchand
}

\section{- To cite this version: \\ Léon Masurel, Carlo Bianca, Annie Lemarchand. Thermostatted kinetic theory approach to the competition between cancer and immune system cells in an inhomogeneous system. 31ST INTERNA- TIONAL SYMPOSIUM ON RAREFIED GAS DYNAMICS: RGD31, 2018, Glasgow, United King- dom. pp.150005, 10.1063/1.5119677 . hal-02324070}

\section{HAL Id: hal-02324070 \\ https://hal.science/hal-02324070}

Submitted on 23 Oct 2019

HAL is a multi-disciplinary open access archive for the deposit and dissemination of scientific research documents, whether they are published or not. The documents may come from teaching and research institutions in France or abroad, or from public or private research centers.
L'archive ouverte pluridisciplinaire HAL, est destinée au dépôt et à la diffusion de documents scientifiques de niveau recherche, publiés ou non, émanant des établissements d'enseignement et de recherche français ou étrangers, des laboratoires publics ou privés. 


\title{
Thermostatted Kinetic Theory Approach To The Competition Between Cancer And Immune System Cells In An Inhomogeneous System
}

\author{
Léon Masurel ${ }^{1}$, Carlo Bianca $^{2}$ and Annie Lemarchand ${ }^{1, \mathrm{a}), \mathrm{b})}$ \\ ${ }^{1}$ Sorbonne Université, Centre National de la Recherche Scientifique CNRS, Laboratoire de Physique Théorique de la \\ Matière Condensée, LPTMC, 4 place Jussieu, case courrier 121, 75252 Paris Cedex 05, France \\ ${ }^{2}$ École Supérieure d'Ingénieurs en Génie Électrique, Productique et Management Industriel, Laboratoire de \\ Recherche en Eco-innovation Industrielle et Energétique, Laboratoire Quartz EA 7393, 13 Boulevard de l'Hautil, \\ 95092 Cergy Pontoise Cedex, France
}

a) Corresponding author: anle@lptmc.jussieu.fr

b)URL: https://www.lptmc.jussieu.fr/users/anle

\begin{abstract}
The competition between a cancer and the immune system are modelled at cell scale in the framework of thermostatted kinetic theory. Cell activation and learning are reproduced by the increase of cell activity during interactions. The fluctuations of system activity are controlled by a thermostat which reproduces the regulation of the learning process and memory loss through cell death. An algorithm, including spatial description and inspired from the direct simulation Monte Carlo (DSMC) method, is used to simulate stochastic trajectories for cell numbers and activities. We focus on the decisive role played by the thermostat. For inefficient thermalization, the divergence of the number of cancer cells is obtained in spite of favored production of immune system cells. Conversely, when the activity fluctuations are controlled, the development of cancer is contained even for weakened immune defenses. These results may be correlated to unexpected clinical observations in the case of different cancers, such as carcinoma, lymphoma, and melanoma.
\end{abstract}

\section{INTRODUCTION}

The competition between immune system cells and cancer cells can be compared to the interactions between immune system cells and bacteria. In both cases, the presence of foreign cells induces a cascade of responses from the immune system [1, 2, 3]. Different types of cells providing specific responses to aggression are involved in the defense mechanism $[4,5]$. Dentritic cells, so-called because of the arms they develop, are able to ingest cancer cells and to isolate antigens. The presentation of antigens to $\mathrm{T}$ cells triggers their activation and proliferation [6]. In particular, killer T cells, able to destroy cancer cells, are formed. However, cancer cells may proliferate and develop the ability to blend into the surrounding tissue, misleading the immune system cells which limit their own production $[7,8]$.

A model of competition between cancer cells and immune system cells should reflect these different interactions as well as the activation and learning processes. With the aim of building a minimal model, we consider a single type of immune system cells $i$, cancer cells $c$, and normal cells $n$. The learning process is reproduced by the increase of a so-called activity $u$ carried by each cell $[9,10,11,12,13,14]$. Thermostatted kinetic theory appears as a suitable framework to model cancer and immune system competition at the cell scale $[15,16,17]$.

In the next section, we describe the chosen model of cell interactions, write the corresponding kinetic equations, and explain how the direct simulation Monte Carlo (DSMC) method has been extended to the present context [18, 19]. The results are given in Section 3. We show that the model reproduces the three E's (elimination, equilibrium, escape) observed in immunotherapy, where an apparent elimination of the tumor precedes a long period of equilibrium, eventually followed by the escape of the cancer cells from the control of the immune system [20]. We point out the 
role played by the control of activity fluctuations in the control of cancer. Section 4 is devoted to conclusions.
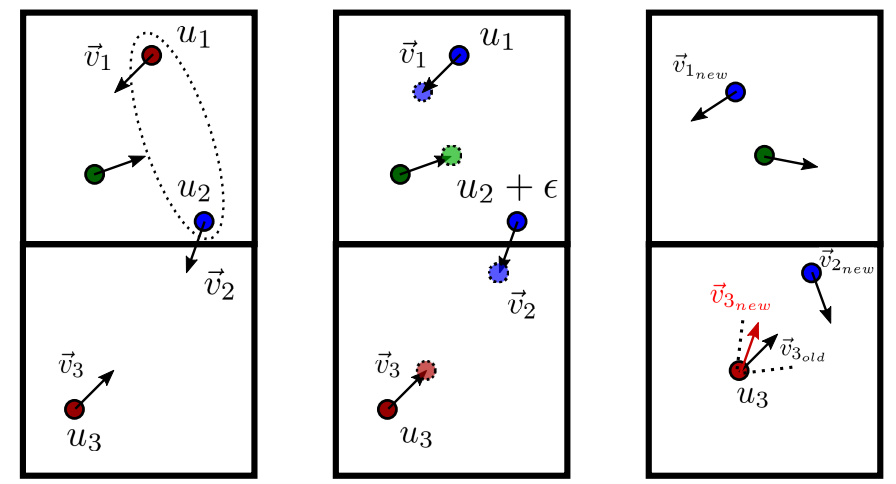

FIGURE 1. Illustration of the algorithm for two spatial boxes: During a time step, cell natures, positions, velocities, and activities are updated. From left to right: The cancer cell 1 and the immune system cell 2 are randomly chosen in a spatial box, the angle between their velocities $\mathbf{v}_{1}$ and $\mathbf{v}_{2}$ is assumed smaller than $\theta_{u}=\pi$ and the activity $u_{2}$ of the immune system cell is assumed larger that the activity $u_{1}$ of the cancer cell. Interaction is accepted according to the appropriate probability, the cancer cell 1 is transformed into an immune system cell 1 and the activity of the immune system cell 2 is increased by $\epsilon$; cell positions are updated, which may result in a change of spatial box; velocity randomization is illustrated for cell 3 , the new velocity $\mathbf{v}_{3 \text { new }}$ is randomly chosen inside an angle of $\pm \theta_{v} / 2=\pi / 6$ around the direction of the former velocity $\mathbf{v}_{3 \text { old }}$. In addition, activities of all cells $i$ are updated according to $\Delta u_{i}=\left(E-\alpha u_{i}\right) \Delta t$.

\section{MODEL, KINETIC EQUATIONS, AND SIMULATION ALGORITHM}

In order to more easily link an interpretable effect in immunotherapy to an ingredient in the model, or even to a control parameter, we have introduced a minimum number of steps in the mechanism $[13,14]$. Specifically, we consider only three processes which include interaction, activation, proliferation or death as follows:

$$
\left\{\begin{array}{l}
c(u)+n\left(u^{\prime}\right) \stackrel{k_{c n}\left(u-u^{\prime}\right) H\left(u-u^{\prime}\right)}{\longrightarrow} c(u+\epsilon)+c\left(u^{\prime}\right) \\
S \longrightarrow n\left(u^{\prime \prime}\right) \\
i(u)+c\left(u^{\prime}\right) \stackrel{k_{i c}\left(u-u^{\prime}\right) H\left(u-u^{\prime}\right)}{\longrightarrow} i(u+\epsilon)+i\left(u^{\prime}\right) \\
c(u)+i\left(u^{\prime}\right) \stackrel{k_{c i}\left(u-u^{\prime}\right) H\left(u-u^{\prime}\right)}{\longrightarrow} c(u+\epsilon)+c\left(u^{\prime}\right)
\end{array}\right.
$$

where $k_{c n}, k_{i c}$ and $k_{c i}$ are constants.

The process given in Eq. (1) includes the mutation of a normal cell into a cancer cell and the division of a cancer cell. A reservoir $S$ is introduced to maintain the number of normal cells constant. The injected normal cell has an activity $u^{\prime \prime}$, randomly chosen from the same distribution $P(u)$ as the one chosen to generate the initial state. The constant $k_{c n}$ is chosen much smaller than $k_{i c}$ and $k_{c i}$ to account for the slower rate of normal cell mutations compared to the interaction rates between cancer cells and immune system cells. The process given in Eq. (2) includes the death of a cancer cell and the division of an immune system cell. Symmetrically, the process given in Eq. (3) includes the death of an immune system cell and the division of a cancer cell. In addition to limiting the number of interaction steps, simultaneously considering the division of immune system cells and the death of cancer cells (or vice-versa) offers the opportunity to add a criterion on the relative activity of an interacting pair. Due to the Heaviside step function $H\left(u-u^{\prime}\right)$, the autocatalytic formation of an immune system cell according to Eq. (2) occurs if the immune 
system cell has a larger activity than the cancer cell, whereas the autocatalytic formation of a cancer cell through Eq. (3) happens if the activity of the cancer cell is larger. The rate of each process is supposed to be proportional to the difference of activities of the interacting pair, which introduces a possible regulation: For example, despite their autocatalytic production through Eq. (2), a large number of immune system cells with a smaller activity than the cancer cells do not necessarily proliferate. Learning is reproduced by the small increase $\epsilon$ of the activity of the cell with the already larger activity before the interaction. With this rule, normal cells never gain activity during interactions, as desired.

In the model, the regulation of cell activity is performed using a thermostat mimicking the loss of information due the action of regulatory $\mathrm{T}$ cells and to cell death which suppresses cells with high activities as well. By analogy with mechanics, we introduce a field $E$ and a friction coefficient $\alpha$, such that $[16,9]$

$$
\frac{\mathrm{d} u_{k}}{\mathrm{dt}}=E-\alpha u_{k}
$$

where $u_{k}$ is the activity of cell $k$. Imposing that the second moment $\left\langle u^{2}\right\rangle$ of the activity of the total number of cells remains constant leads to

$$
\alpha=\frac{\langle u\rangle E}{\left\langle u^{2}\right\rangle}
$$

where $\langle u\rangle$ is the mean activity of the system.
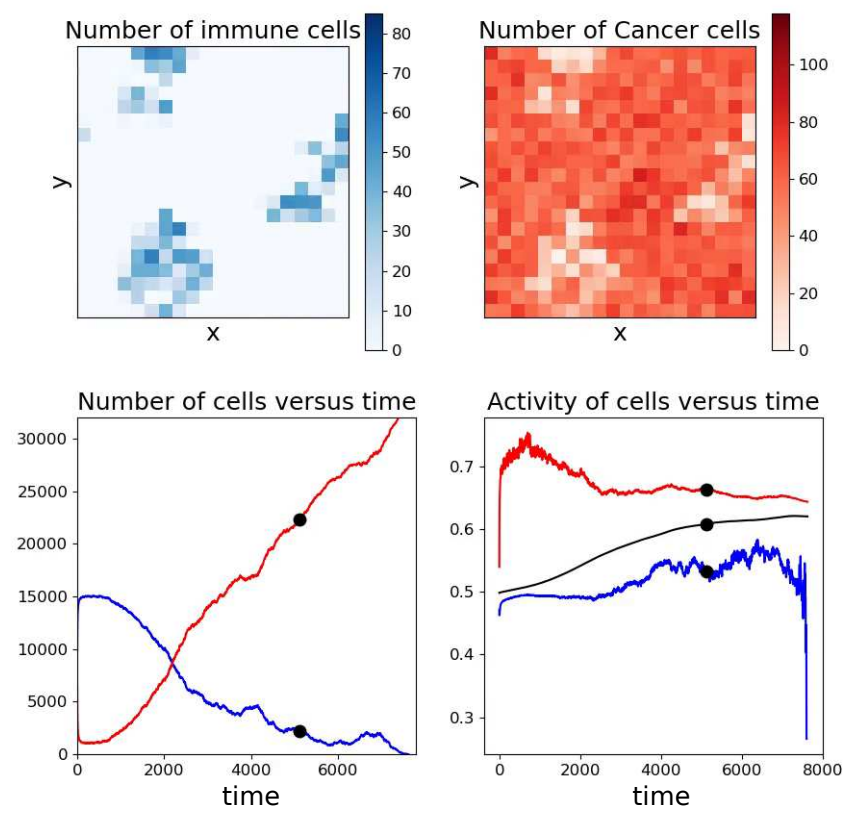

FIGURE 2. Spatial distribution of immune system cells (top left) and cancer cells (top right) at time $t=5200$ indicated by a disc on the evolution of cell numbers (bottom left) and cell activities (bottom right). Contrary to the number of immune system cells, the number of cancer cells initially drops and finally diverges. The mean activity of the cancer cells is always larger than the mean activity of the immune system cells, the line in between is the mean activity of the system. Parameter values: System size $l_{x}=l_{y}=20, \Delta l=1$, initial number of cells in spatial box $N_{n}(t=0)=50, N_{i}(t=0)=N_{c}(t=0)=20$, mean $\mu=0.5$ and standard deviation $\sigma=0.2$ of the initial Gaussian distribution $P(u)$ of cell activity, time step $\Delta t=1$, rate constants $k_{i c}=0.1, k_{c i}=0.01$, $k_{c n}=10^{-5}$, angle of interaction $\theta_{u}=\pi$, activity increase $\epsilon=10^{-3}$, cell speed $v=0.0333$, probability of velocity deflection $p_{v}=0.1$, angle of velocity deflection $\theta_{v}=\pi / 3$, field associated with the thermostat $E=3.5 \times 10^{-4}$.

According to the thermostatted kinetic theory, the kinetic equations for the probability distributions $f_{j}$ of the 
three kinds of cells, $j=c, i, n$ are given by:

$$
\left(\partial_{t}+\mathbf{v} \cdot \nabla_{\mathbf{x}}\right) f_{j}(t, \mathbf{x}, \mathbf{v}, u)+\partial_{u}\left((E-\alpha u) f_{j}\right)=I_{j}+V_{j}
$$

where the interaction term $I_{c}$ for cancer cells obeys

$$
\begin{aligned}
I_{c} & =\int_{\mathbb{R}^{+}} \kappa_{c n}\left(u-\epsilon, u^{\prime}\right) f_{c}(t, \mathbf{x}, \mathbf{v}, u-\epsilon) f_{n}\left(t, \mathbf{x}, \mathbf{v}^{\prime}, u^{\prime}\right) \mathrm{d} u^{\prime} \mathrm{d} \mathbf{v}^{\prime} \\
& +\int_{\mathbb{R}^{+}} \kappa_{c n}\left(u^{\prime}, u\right) f_{c}\left(t, \mathbf{x}, \mathbf{v}, u^{\prime}\right) f_{n}(t, \mathbf{x}, \mathbf{v}, u) \mathrm{d} u^{\prime} \mathrm{d} \mathbf{v}^{\prime} \\
& -\int_{\mathbb{R}^{+}} \kappa_{i c}\left(u^{\prime}, u\right) f_{c}(t, \mathbf{x}, \mathbf{v}, u) f_{i}\left(t, \mathbf{x}, \mathbf{v}, u^{\prime}\right) \mathrm{d} u^{\prime} \mathrm{d} \mathbf{v}^{\prime} \\
& +\int_{\mathbb{R}^{+}} \kappa_{c i}\left(u-\epsilon, u^{\prime}\right) f_{c}(t, \mathbf{x}, \mathbf{v}, u-\epsilon) f_{i}\left(t, \mathbf{x}, \mathbf{v}, u^{\prime}\right) \mathrm{d} u^{\prime} \mathrm{d} \mathbf{v}^{\prime} \\
& +\int_{\mathbb{R}^{+}} \kappa_{c i}\left(u^{\prime}, u\right) f_{c}\left(t, \mathbf{x}, \mathbf{v}, u^{\prime}\right) f_{i}(t, \mathbf{x}, \mathbf{v}, u) \mathrm{d} u^{\prime}
\end{aligned}
$$

with $\kappa_{c j}\left(u^{\prime}, u\right)=k_{c j}\left(u^{\prime}-u\right) H\left(u^{\prime}-u\right) H\left(\theta_{u}-\left|\angle\left(\mathbf{v}, \mathbf{v}^{\prime}\right)\right|\right)$ for $j=n, i$ and $\kappa_{i c}\left(u^{\prime}, u\right)=k_{i c}\left(u^{\prime}-u\right) H\left(u^{\prime}-u\right) H\left(\theta_{u}-\left|\angle\left(\mathbf{v}, \mathbf{v}^{\prime}\right)\right|\right)$ with $0<\theta_{u} \leq \pi$. The notation $\angle\left(\mathbf{v}, \mathbf{v}^{\prime}\right)$ refers to the angle between the vectors $\mathbf{v}$ and $\mathbf{v}^{\prime}$. The condition on the directions of the velocities of the interacting couple ensures that the two cells remain close during a sufficient time for activation and learning to take place. The interaction term $I_{i}$ for immune system cell is:

$$
\begin{aligned}
I_{i} & =\int_{\mathbb{R}^{+}} \kappa_{i c}\left(u-\epsilon, u^{\prime}\right) f_{c}\left(t, \mathbf{x}, \mathbf{v}, u^{\prime}\right) f_{i}(t, \mathbf{x}, \mathbf{v}, u-\epsilon) \mathrm{d} u^{\prime} \mathrm{d} \mathbf{v}^{\prime} \\
& +\int_{\mathbb{R}^{+}} \kappa_{i c}\left(u^{\prime}, u\right) f_{c}(t, \mathbf{x}, \mathbf{v}, u) f_{i}\left(t, \mathbf{x}, \mathbf{v}, u^{\prime}\right) \mathrm{d} u^{\prime} \mathrm{d} \mathbf{v}^{\prime} \\
& -\int_{\mathbb{R}^{+}} \kappa_{c i}\left(u^{\prime}, u\right) f_{c}\left(t, \mathbf{x}, \mathbf{v}, u^{\prime}\right) f_{i}(t, \mathbf{x}, \mathbf{v}, u) \mathrm{d} u^{\prime} \mathrm{d} \mathbf{v}^{\prime}
\end{aligned}
$$

For normal cells, the interaction term $I_{n}$ reads:

$$
\begin{aligned}
I_{n} & =-\int_{\mathbb{R}^{+}} \kappa_{c n}\left(u^{\prime}, u\right) f_{c}\left(t, \mathbf{x}, \mathbf{v}, u^{\prime}\right) f_{n}(t, \mathbf{x}, \mathbf{v}, u) \mathrm{d} u^{\prime} \mathrm{d} \mathbf{v}^{\prime} \\
& +P(u) \int_{\mathbb{R}^{+}} \int_{\mathbb{R}^{+}} k_{c n}\left(u^{\prime}-u\right) H\left(u^{\prime}-u^{\prime \prime}\right) H\left(\theta_{u}-\left|\angle\left(\mathbf{v}, \mathbf{v}^{\prime}\right)\right|\right) f_{c}\left(t, \mathbf{x}, \mathbf{v}, u^{\prime}\right) f_{n}\left(t, \mathbf{x}, \mathbf{v}, u^{\prime \prime}\right) \mathrm{d} u^{\prime} \mathrm{d} u^{\prime \prime} \mathrm{d} \mathbf{v}^{\prime}
\end{aligned}
$$

All the cells have the same speed, which is conserved during the evolution. Only the directions of the cell velocities change. The turning operator $V_{j}$ which models the velocity-jump process is a stochastic term given by:

$$
V_{j}=\int_{D_{v}}\left(T\left(\mathbf{v}^{\prime}, \mathbf{v}\right) f_{j}\left(t, \mathbf{x}, \mathbf{v}^{\prime}, u\right)-T\left(\mathbf{v}, \mathbf{v}^{\prime}\right) f_{j}(t, \mathbf{x}, \mathbf{v}, u)\right) \mathrm{d} \mathbf{v}^{\prime}
$$

where the turning kernel obeys $T\left(\mathbf{v}, \mathbf{v}^{\prime}\right)=p_{v} H\left(\theta_{v}-\left|\angle\left(\mathbf{v}, \mathbf{v}^{\prime}\right)\right|\right)$, where $p_{v}$ is the probability that the velocity is turned clockwise or anticlockwise by an angle smaller than $\theta_{v} / 2$ with $0<\theta_{v} \leq \pi$.

The direct simulation Monte Carlo (DSMC), initially used as a direct simulation of the Boltzmann equations associated with a dilute gas $[18,19]$, has been adapted to simulate the kinetic equations given in Eq. (6) for $j=c, i, n$. The algorithm is illustrated by the scheme given in Fig. 1. During the time step $\Delta t$, interactions are performed between cells belonging to a same spatial box of length $\Delta x$ according to the mechanism given in Eqs. (1-3), which leads to updating the natures $j$ and the activities of the cells. Cell positions are updated according to their velocities. The directions of cell velocities are randomized following the turning operator given in Eq. (10); Cell velocity is shifted by a randomly chosen angle in the interval $\left[-\theta_{v}, \theta_{v}\right]$ with a probability $p_{v}$. Finally, thermalization, i.e. the control of activity fluctuations, leads to activity update following Eqs. $(4,5)$. 

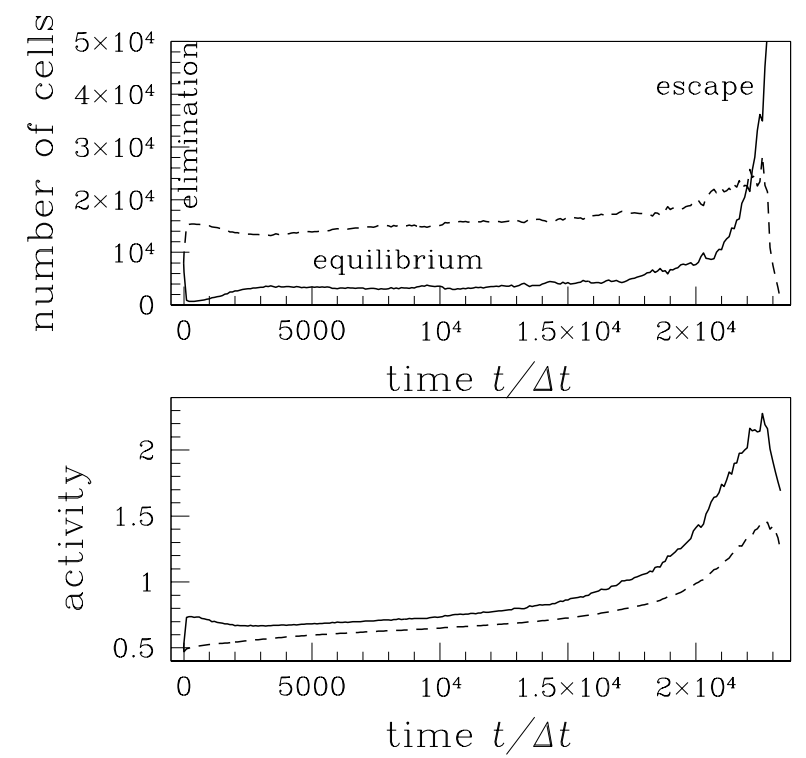

FIGURE 3. Typical results at small field $E=3 \times 10^{-4}$. Top: Number of immune system cells (dashed line) and cancer cells (solid line) in the system versus time. Bottom: Mean activity of immune system cells (dashed line) and cancer cells (solid line) versus time. Illustration of the three E's (elimination, equilibrium, escape) of immunotherapy. Except for the field value, the parameter values are given in the caption of Fig. 2 .

\section{RESULTS}

The aim is to study the ability of the immune system to control a tumor initially occupying the entire simulated system. The immune system is a priori boosted and we impose that the constant $k_{i c}$ associated with the autocatalytic production of immune system cells through Eq. (2) is ten times larger than the constant $k_{c i}$ associated with the autocatalytic production of cancer cells through Eq. (3). The results are illustrated in Fig. 2 for an initially homogeneous condition with the same number of cancer cells, immune system cells and normal cells in each spatial box. The top subfigures show the spatial anticorrelations between the numbers of cancer cells and immune system cells: At a given time, the remaining clusters of immune cells are located where cancer cells are most depleted. The increase of the number of cancer cells and the destruction of the immune system cells shown in Fig. 2 are not intuitive for $k_{i c} \gg k_{c i}$. The final proliferation of cancer cells is observed due to the advantage arising from their larger activities, leading to faster rates for autocatalytic production of cancer cells through the step given in Eq. (3).

The results shown in Fig. 2 are obtained for an intermediate value of the field $E$ controlling the efficiency of the thermostat, i.e. the level of activity fluctuations. Depending on the field $E$, very different evolutions of cell numbers and activities are obtained. Figure 3 give the results for a smaller value of $E$ than in Fig. 2 whereas Fig. 4 is associated with a larger value of $E$ than in Fig. 2. In Fig. 3, for inefficient thermalization, the number of cancer cells rapidly drops and then remains in a quasi steady state before exploding. This typical behavior is clinically observed and is called the three E's of immunotherapy for elimination, equilibrium and escape of cancer from immune system surveillance [20]. We already reproduced this phenomenon in the framework of a homogeneous description of the system without spatial dependence. The results given in Fig. 3 show the ability of the present spatial description to account for the three E's, a phenomenon which limits the chances of success of immunotherapy. On the contrary, the results displayed in Fig. 4 for a large field $E$ show a stabilization of the activities of cancer cells and immune system cells to the same steady value. All cells in the system eventually have the same activity. In these conditions, the rates of the processes given in Eqs. (1-3) vanish and the numbers of cancer cells and immune system cells converges to steady values, $N_{c}^{\text {end }}$ and $N_{i}^{\text {end }}$, respectively. Hence, for a sufficient thermalization, cancer is controlled by the immune 

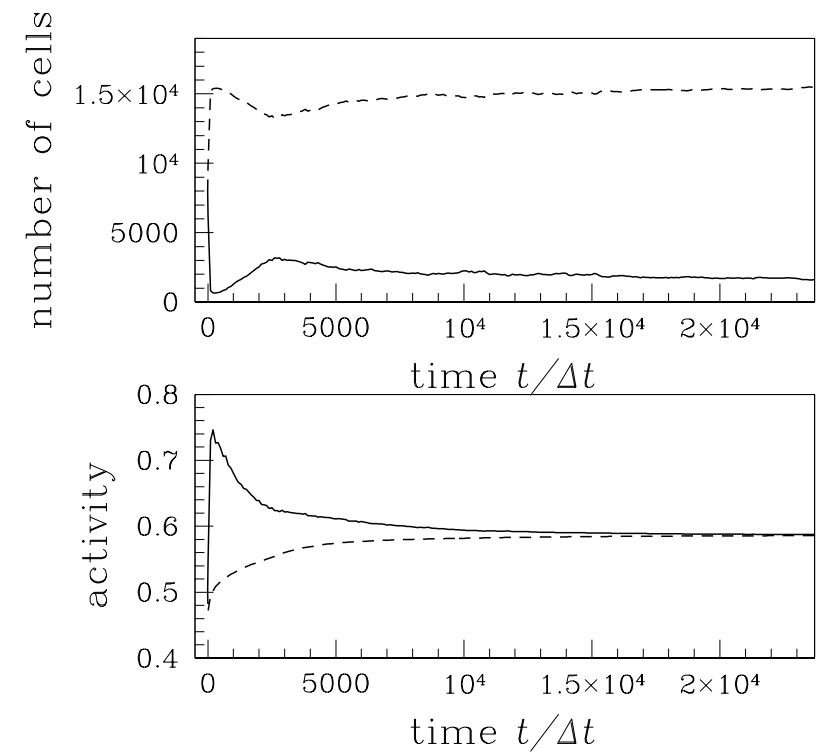

FIGURE 4. Same caption as in Fig. 3 for a large field $E=4 \times 10^{-4}$. Illustration of cancer control.

system. For $k_{i c} \gg k_{c i}$, we obtain a larger steady value of the numbers of immune system cells $N_{i}^{\text {end }} \gg N_{c}^{\text {end }}$. The result can be immediately extended to the case $k_{c i}>k_{i c}$, for which cancer is still controlled but for a higher steady value of the numbers of cancer cells $N_{c}^{\text {end }}>N_{i}^{\text {end }}$. The paradoxical coexistence of cancer cells and T cells remains a subject of debate in immunotherapy and the present work proposes a possible mechanism leading to it [21].

The crucial role played by the thermostat is pointed out in Fig. 5. The probability of observing a final state in which all the immune system cells have been destroyed or with nonvanishing steady numbers of both cancer cells and immune system cells sensitively varies with the field $E$ controlling thermalization. A sharp transition between cancer escape and cancer control is observed for the intermediate value of the field $E$ considered in Fig. 2. The model offers some hints to control cancer by immunotherapy: As a result of the simulations, the processes which tends to limit the fluctuations of cell activity are favorable. Consequently and contrary to intuition, the lifetime of the cells, including the one of the immune system cells, should not be too long to prevent the formation of highly educated cells with a high activity which would result in increasing the second moment of system activity and enable large fluctuations of the number of cancer cells, offering them a possibility to escape from the control of the immune system cells.

\section{CONCLUSION}

The interactions between a tumor and the immune system are described at the cell scale in the framework of thermostatted kinetic theory. We use a model of cell interactions having already given account of the three 3E's of immunoediting [20]: Elimination, equilibrium, and escape from immune system control have been reproduced in an homogeneous system $[13,14]$. In the present paper, we have introduced a spatial description of the phenomenon, taking into account cell positions and velocities. Cell interactions may modify cell type and cell activity, a quantity accounting for the level of learning of immune system cells exposed to antigens as well as the degree of invisibility reached by cancer cells. Interestingly, memory loss related to cell death and regulation of the immune system are reproduced by the effect of a "thermostat", which regulates activity fluctuations in an analogous way as an actual thermostat controls temperature fluctuations. An algorithm inspired by the direct simulation Monte Carlo method $[18,19]$ is used to numerically solve the kinetic equations for the probability densities of normal cells, cancer cells, and immune system cells. The simulations generate stochastic trajectories for the numbers of cells and the activity of 


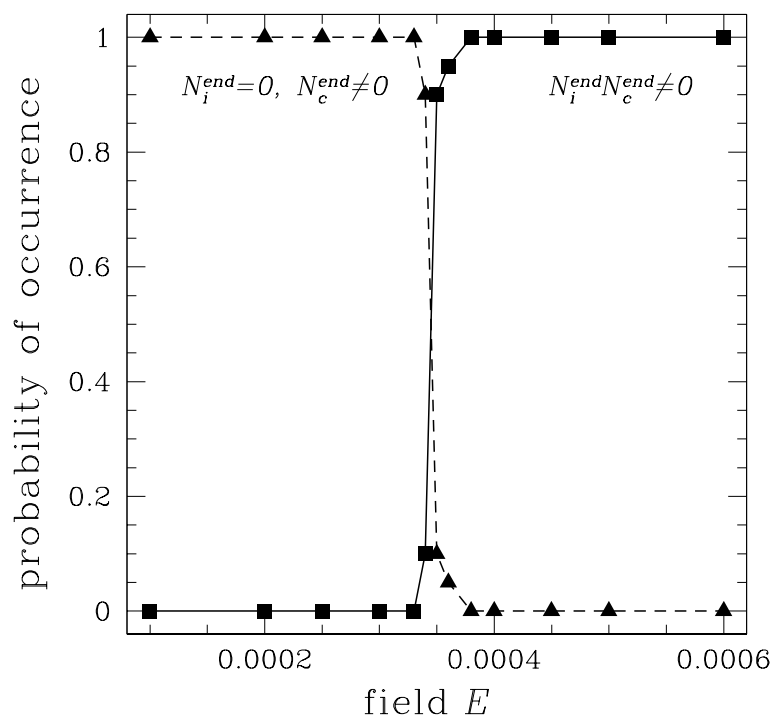

FIGURE 5. Probability of occurrence of the two evolutions shown in Figs. 3 and 4 versus field $E$ associated with the thermostat. Dashed line and triangles: Vanishing number of immune system cells at the end of the simulations, $N_{i}^{\text {end }}=0$. Solid line and squares: Nonvanishing numbers of both immune system cells and cancer cells at the end of the simulations, $N_{i}^{\text {end }} N_{c}^{\text {end }} \neq 0$. Except for the field value, the parameter values are given in the caption of Fig. 2. The statistics is based on 20 runs for each field value. For $E<3.5 \times 10^{-4}$, cancer escapes from immunosurveillance, for $E>3.5 \times 10^{-4}$, cancer is controlled.

the system.

We focus on the effect of the thermostat, i.e. on the control of activity fluctuations using a field $E$. We conclude that thermalization is favorable to cancer surveillance. For values of the field $E$ larger than a critical value, the cancer cells are not eliminated but their number converges toward a steady value. The cancer is controlled in a sufficiently dissipative system where the fluctuations of activity are regulated. Dissipation of activity occurs through cell death. Our results may explain the poor performance of immunotherapy in the case of some patients, for which mutations of cancer cells, all the more likely as cell life is long, may induce adaptive resistance to the treatment [22]. Similarly, although regulatory $\mathrm{T}$ cells are known to suppress $\mathrm{T}$ cell and hinder the immune response against cancer, their thermalizing role could explain why high levels of regulatory $\mathrm{T}$ cells may be associated with a positive prognosis, for example in the case of colorectal carcinoma and follicular lymphoma [23, 24].

As a perspective, we intend to perform a sensitivity analysis of the different parameters of the model and in particular to study the effect of cell speed on the formation or destruction of clusters of cancer cells for different inhomogeneous initial conditions.

\section{REFERENCES}

[1] T. Blankenstein, P. G. Coulie, E. Gilboa and E. M. Jaffee, Nat. Rev. Cancer 12, 307 (2012).

[2] M. D. Vesely and R. D. Schreiber, Ann. N.Y. Acad. Sci. 1284, 1 (2013).

[3] I. Sagiv-Barfi, D. K. Czerwinski, S. Levy, I. S. Alam, A. T. Mayer, S. S. Gambhir, and R. Levy, Sci. Transl. Med. 10, eaan4488 (2018).

[4] C. A. Siegrist, in Vaccines (5th ed), edited by S. A. Plotkin, W. A. Orenstein, and P. A. Offit (Saunders Elsevier, New York, 2008) pp. 17-36. 
[5] O. Leo, A. Cunningham, P. L. Stern in Understanding Modern Vaccine, Perspectives in Vaccinology, Vol. 1, edited by N. Garçon and P. L. Stern (Elsevier B. V., Amsterdam, 2011) pp. 25-59.

[6] P. Guermonprez, J. Valladeau, L. Zitvogel, C. Théry, and S. Amigorena, Annu. Rev. Immunol. 20, 621 (2002).

[7] G. P. Dunn, A. T. Bruce, H. Ikeda, L. J. Old and R. D. Schreiber, Nature immunology 3, 991 (2002).

[8] F. H. Igney and P. H. Krammer, J. Leukoc. Biol. 71, 907 (2002).

[9] C. Bianca, Nonlinear Anal. Real World Appl. 13, 2593 (2012).

[10] C. Bianca and C. Dogbe, Nonlinearity 27, 2771 (2014).

[11] C. Bianca and A. Lemarchand, Commun. Nonlinear Sci. Numer. Simul. 20, 14 (2015).

[12] C. Bianca, C. Dogbe and A. Lemarchand, Acta Applicandae Mathematicae 189, 1 (2015).

[13] C. Bianca and A. Lemarchand, J. Chem. Phys. 145, 154108 (2016).

[14] L. Masurel, C. Bianca, and A. Lemarchand, Physica A 506, 462 (2018).

[15] C. Cercignani, R. Illner and M. Pulvirenti, The mathematical theory of dilute gases (Springer, New York, 1994).

[16] B. Wennberg and Y. Wondmagegne, J. Stat. Phys. 124, 859 (2006).

[17] N. Bellomo, C. Bianca, and M. Delitala, Phys. Life Rev. 6, 144 (2009).

[18] G. A. Bird, Molecular Gas Dynamics and the Direct Simulation of Gas Flows (Clarendon, Oxford, 1994).

[19] F. Alexander and A. Garcia, Computers in Physics 11, 588 (1997).

[20] G. P. Dunn, L. J. Old and R. D. Schreiber, Annu. Rev. Immunol. 22, 329 (2004).

[21] G. Marincola and F. M. Marincola, in Immunotherapy of Cancer, ed. Mary L. Disis, p. 317 (Humana Press, Totowa, 2006).

[22] J. M. Zaretsky, A. Garcia-Diaz, D. S. Shin, H. Escuin-Ordinas, W. Hugo, S. Hu-Lieskovan, D. Y. Torrejon, G. Abril-Rodriguez, S. Sandoval, L. Barthly, J. Saco, B. Homet Moreno, R. Mezzadra, B. Chmielowski, K. Ruchalski, I. P. Shintaku, P. J. Sanchez, C. Puig-Saus, G. Cherry, E. Seja, X. Kong, J. Pang, B. Berent-Maoz, B. Comin-Anduix T. G. Graeber, P. C. Tumeh, T. N. Schumacher, R. S. Lo, A. Ribas, N. Engl. J. Med. 375,819 (2016).

[23] J. Wang and X.-Y. Ke, J. Hematol. Oncol. 4, 50 (2011).

[24] K.-S. Le, M.-L. Thibult, S. Just-Landi, S. Pastor, F. Gondois-Rey, S. Granjeaud, F. Broussais, R. Bouabdallah, R. Colisson, C. Caux, C. Ménétrier-Caux, D. Leroux, L. Xerri, and D. Olive, Cancer Res. 76, 4648 (2016). 